Juan De Luigi

\title{
Giovanni Papini
}

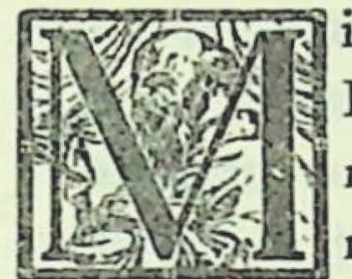

padre estudió en Florencia y en la Universidad de Pisa. Cuando joven conoció a Giovanni Papini. Al parecer fué sólo un conocimiento superficial. Tal vez lo nombró antes que el nombre de Papini traspasara los límites de Florencia, de la Toscana y de Italia. Tal vez. Pero los escritores que más nombraba como conocidos y aun como amigos, eran Domenico Giuliotti y Ferdinando Paolieri. Conservaba entre sus recuerdos de estudiante, algunas revistas. Una de ellas se llamaba Il Bruscolo. Después de la primera guerra mundial me habló también de Papini; pero no había pertenecido ni a su grupo ni, al parecer, había tenido gran admiración por su personalidad o por su obra.

Con Giuliotti, Giovanni Papini escribió el Diccionario del hombre salvaje. Lo he vuelto a hojear en estos días. No deseo formular un juicio sobre él ya que, mal que mal, está dentro de toda la obra de Papini. Lo que puede decirse del libro puede decirse de toda la obra. Esto podrá parecer o extraño o superficial. No lo creo así. Sé bien que toda verdad específica se transforma en una falsedad o en una deformación cuando se la amplía hasta lo general. Y entiendo por verdad lo que todos debiéramos entender, aunque no siempre todos lo entiendan así: realidad es lo que existe con independencia de toda relación con un sujeto. Verdad es la identidad aproximada 
entre esa realidad que no necesita consideración para ser y la representación que de ella nos hacemos.

Pues bien; opino que la obra de Papini, la de cuando fué muchacho que aspiraba a redactar una enciclopedia universal, la de cuando fué pragmatista, la de cuando fué nietzscheano, la de cuando se convirtió al catolicismo, está dentro de un mismo molde fácilmente reconocible. Como primera tentativa aproximada para definirlo, yo propondría la siguiente frase de las palabras preliminares a la Storia di Cristo (Vallecchi Editori, Firenze, pág. XXVI): L'odio, talvolta, non é che amore imperfetto $e$ non consapevole di sé; $e$ in tutti $i$ modi é miglior tirocinio d'amore della indifferenza.

Esto nos daría un Papini cuya característica casi esencial sería el amor imperfecto y que no tiene conciencia de sí mismo. Si consideráramos su vida con cierta superficialidad, podríamos llegar a la conclusión contraria: la de que fué un hombre de amor perfecto y consciente de sí mismo. Esto, seguramente, lo alegarían con mayor fuerza los católicos a cuya creencia adhirió y en la que ha muerto. Sin embargo, aunque el lapso de su catolicismo haya sido el final en su existencia y el más largo entre los que forman su devenir, creo que no demostró en él un mayor convencimiento, una mayor intensidad que en sus amores anteriores. $\mathrm{Y}$ que en sus odios anteriores. Igual ardor en la defensa de lo que él creía en ese momento, igual intemperancia verbal muy florentina y muy toscana en contra de los que no estaban de acuerdo con él. Es decir, amor que se manifestaba en gran parte en odio, es decir en amor imperfecto e inconsciente de sí mismo, tal como él lo definió.

Esta pareja de contradictorios alcanzó, según mi modo de ver, la síntesis en la última obra del florentino muerto. Tal vez la más nombrada en la actualidad entre las suyas, la más criticada y, secretamente, sin duda la más estimada. La del perdón del Diablo. La de la absolución definitiva de todos los pecadores y del máximo pecador, autor del máximo pecado, el del orgullo, Lucifer.

Expongo, naturalmente, mi opinión. Puede estar equivocada. Por lo demás, entre mis defectos, nunca he tenido el de tratar de objeti- 
var mis opiniones. Si tuviera más espacio, trataría de probarla y creo que no me faltarían hechos y citas más que abundantes para hacerlo. Como el espacio no me lo permite, me remito a la interpretación de los que hayan leído en todo o en parte a Papini y lo hayan leído con sinceridad y honradez sin partir, previamente de consignas o de clasificaciones que por estar demasiado a la mano, por ser sólo lugares comunes son perfectamente absurdas y sirven sólo para tratar de enmascarar la falta de pensamiento propio, de reflexión y de sinceridad.

En ella Papini, destruía tal vez sin darse cuenta todo el verdadero poder de la Iglesia que cree en el perdón de los pecados mientras dura esta vida, pero que cree también en el castigo o en la salvación eterna después de ella. Como literato iba también en contra de su gran compatriota, florentino hasta la médula como él, espantosamente terrible en contra de sus enemigos y exaltador de un amor más que terreno y por consiguiente no terreno: Dante Alighieri a quien Papini dedicó uno de sus más hermosos libros. Me refiero a Dante vivo. Sobre la puerta del Infierno Alighieri leyó, entre otras cosas, lo siguiente:

\section{Dinanzi a mé non fur cose create se non eterne ed io etcrna duro. Lasciate ogni speranza voi ch'entrate.}

(Divina Comedia, Infierno. Canto III).

Pero, tal vez, Papini con ese perdón definitivo llegó, por fin, a lo que nunca había poseído en su vida: al amor perfecto. Se perdonó a sí mismo. Porque, la verdad es que Papini odió y amó su propio ser interior. Trasladó a los demás lo que de él no le placía, y trasladó, también a los demás, seres imaginarios o abstractos, lo que de él le parecía y esto en el sentido más moral y amplio del verbo "placer". Podrá ser una irreverencia; pero la parte polémica de Papini me ha recordado siempre a Filippo Argenti, tan nombrado en el Decame- 
rón, de Boccaccio y a quien Dante pinta en el canto octavo en el pantano donde están sumidos los iracundos. No, seguramente, por lo que fué Filippo Argenti en vida ni por la ira con la que se arroja sobre la barca que impulsa Flegias y en la que navegan Dante y la sombra de Virgilio, sino por el furor con que Argenti se martiriza a sí mismo.

Il fiorentino spirito bizzarro

in sé medesmo si volvea coi denti.

(Divina Comedia, Infierno. Canto VIII).

Esto puede pasar por una reducción a la subjetividad. Los que me lean, si lo hacen hasta el fin, verán que no es así. Es sólo una explicación del motor fundamental de Giovanni Papini. Una tentativa de explicación. Una consideración de lo objetivo y de su reflejo en lo subjetivo. Una explicación que comprende el perdón de Papini hacia sí mismo y al mismo tiempo, la absolución del hombre que él odió desde su Vida de Cristo, pero con un odio que ero sólo un amor imperfecto y no consciente de sí mismo. Me refiero al gran Federico Nietzsche, al que dedicó invectivas sin calidad en las palabras preliminares de la Storia di Cristo. Al autor del Anticristo que también sería perdonado en el perdón general y final.

Esta es sólo una media explicación. La fundamental sería, a mi modo de ver, la siguiente: Un autor que tuvo sólo contactos mediatos e intermitentes con la realidad. No con la realidad del pensamiento escrito, del arte escrito, sino con el gran campo de la realidad de la que pensamiento y arte son reflejos. Hay que leer las páginas iniciales de Uomo Finito (Vallecchi, Firenze); hay que tratar de sentir ese desconsolado panorama de la niñez triste, solitaria, taciturna, antipática. De ese muchacho que quería entrar en contacto con el mundo sólo a través de los libros y que llegó sólo imperfectamente a vivir partes de la realidad. No era el que siguió el único camino posible. Tenía muchos. Pero siguió el que fué su vida. Batallas por 
el pragmatismo, batallas para ser el hombre Dios, arribó a la creencia en otro Dios que no era él, pero por el que se sentía comprendido y al final del amor y del perdón para todos. Con ello desaparecía la finalidad de la vida del cristianismo. Pero Papini había resuelto su problema. Su obra es también una comedia en el sentido que Dante Alighieri usa para su libro máximo. No voy a comparar. La diferencia entre ambos es enorme. Pero las semejanzas también son grandes. $\mathrm{Y}$ no solamente con Dante Alighieri. También con todos los grandes toscanos de la historia. Léase con cuidado a Dante o a Boccaccio; léase a Poliziano, a Guicciardini o a Macchiavelli, considérese la historia de la república florentina para no citar más que una parte de la historia toscana. O si se quiere, estúdiese a Miguel Angel y a Benvenutto Cellini sobre todo en su autobiografía y entre los cuasi contemporáneos a Francesco Domenico Guerrazzi o a Giosué Carducci. Todos tienen un distintivo: un profundo y descomunal caos interior sobre el que cada cual trata de tejer una armoniosa teoría que siempre es inferior al caos. Siempre. Todos ellos son grandes, no por sus explicaciones sino por ese caos, por ese pathos que de pronto irrumpe como una invasión de bestias furiosas en un panorama armoniosamente trazado. No conozco otro caso colectivo que de tal manera se prolongue en la historia. Ni me atrevo a calificarlo. Papini fué también una demostración de él. Más que sus antepasados creyó poder llegar a una superación completa y definitiva de los contradictorios. Su mundo es un mundo de pensamientos y un mundo simbólico. Esto no quiere decir irreal. A veces, la historia lo demuestra, a través del símbolo el artista ha podido llegar a una comprensión y representación profunda de la realidad. 